\title{
Modelling Demographic Relationships
}

\author{
G. Phillips $^{\text {a }}$ \\ ${ }^{a}$ School of Mathematics and Statistics, University of Sydney, Australia \\ Email: geoffp@maths.usyd.edu.au
}

\begin{abstract}
This paper is based on adapting the Leslie population model to show the relationship between an aging population and immigration. The recent Government Report (Intergenerational Report, 2015) raised a major concern about the future standard of living in Australia with an aging population in the years 2015 to 2055. Unfortunately, the Report predicted falling living standards but neglected to study the effects of other parameters on these predictions. Quite a simple analysis using the modified Leslie model shows a different picture, including both the dynamics and long term effects of immigration on living standards. The assumptions about life expectancy in the Leslie model can be varied to allow for a large proportion of the population living to one hundred years of age. The results are described and also show how immigration can be of advantage in future Australian living standards.

Another simple model (Piketty, 2014) shows the effects of the changing role of Capital since 1945 and provides an insight into the likely distribution of wealth and income in the years 2015 to 2055 in Australia. The predictions of the two models (Leslie and Piketty) are combined to provide a more complete picture of living standards of an aging population in Australia in the years 2015 to 2055.
\end{abstract}

Keywords: Aging population, immigration, Leslie model 


\section{INTRODUCTION}

The recent Government Report (Intergenerational Report, 2015) on the implications of changing demographics in Australia has raised concern among politicians and the general public that living standards will fall progressively in the next fifty years because of the greater proportion of retirees. Immigration is an obvious way to change the proportion of working people to retirees, this paper will show how this is effect can be quantified in the long term, using the Leslie model. Another factor relevant to the long term living standards of Australians is the growing importance of assets acquired by people during their lifetime. This is a reflection of the growing importance of Capital in the world economy (Piketty, 2014) since 1945.

\section{THE LESLIE MODEL}

The Leslie Model is used to model the changes in a population over a period of time. The population is divided into groups based on age classes. The model is based on matrix operation on a vector containing numbers of a population in each individual class. For example in a population with average age ranges 0 - 19, 20 - 39, 40 -59 and $60-79$ years, the vector might be

$$
v=\left(\begin{array}{l}
5 \\
6 \\
3 \\
1
\end{array}\right)
$$

with an appropriate scaling such as 1.5 million.

An example of a Leslie Matrix is as below and shows birth rates for each class along the top row and survival rates in the off-diagonal.

$$
L=\left(\begin{array}{cccc}
0 & 0.85 & 0.15 & 0 \\
1 & 0 & 0 & 0 \\
0 & 0.95 & 0 & 0 \\
0 & 0 & 0.85 & 0
\end{array}\right)
$$

A useful analysis which can be applied to the Leslie matrix is to calculate the principal eigenvalue of the corresponding eigenvector. By a theorem of Frobenius for non-negative matrices, there is only one positive eigenvalue $\lambda \approx 1.0$. This eigenvalue is the long term rate of growth of the population, $G=100(\lambda-1)$ (in the example very close to zero growth). The eigenvector shows the long terms proportions of the population in each class:

$$
w \approx\left(\begin{array}{l}
5 \\
5 \\
5 \\
4
\end{array}\right)
$$

One of the results most discussed from (Intergenerational Report, 2015) was the ratio of employed people to retirees in the Australian population from 1990 to 2055. This ratio was 6.1 in 1990, falling to 4.5 in 2015 and predicted to be 2.7 in 2055. This decrease is seen as an issue for the future standards of living.

In the Leslie model described above, the ratio of employed to retirees will stabilise at 2.5 in the long term. Even if the ratio starts at 9.0 it will be close to 2.5 in less than fifty years.

\section{MODIFYING THE LESLIE MODEL}

The Leslie Model can easily be modified to include immigration as follows. If the number is row 2, column 2 of the Leslie Matrix from zero to 1.0,

$$
M=\left(\begin{array}{cccc}
0 & 0.85 & 0.15 & 0 \\
1 & 1.0 & 0 & 0 \\
0 & 0.95 & 0 & 0 \\
0 & 0 & 0.85 & 0
\end{array}\right)
$$

there is a quite different result in the long term ratio of employed to retirees which stabilises at a value of 6.0. The principal eigenvalue for this calculation is 1.59 corresponding to a 2.3 percent rate of growth of population from immigration. (The twentieth root of 1.59 is about 1.023). 
But our simplified model does not take into account the expectations of most people living to over 90 years of age. A simple modification made by expanding the Leslie Matrix to $5 \times 5$ to include an age range $80-100$ with a $75 \%$ chance of surviving from 60-80 to 80-100 results in the long term ratio of employed to retirees stabilising at a value of 4.0. The rate of population increase is 2.3 percent per annum as before.

\section{WHAT CONCLUSIONS CAN BE DRAWN}

Such a simplified Leslie population model cannot represent the actual situation in Australia but it does show that there are policies which can dramatically change the conclusions in (Intergenerational Report, 2015). The model also shows that in a population with zero population growth, life expectancy to perhaps 90 and retiring age at 60 will have difficulty funding pensions.

But Australia is in a favourable position compared to other OECD countries, which all currently have higher ratios of employed to retirees (Intergenerational Report, 2015) and do not want increased populations. Australia has a positive immigration policy and is better situated to increase population than are many other countries.

\section{CONTRIBUTION OF CAPITAL TO NATIONAL INCOME}

National Income can be seen as coming from two sources: Capital and Labour, (as described much more adequately in (Piketty, 2014)). As taxation of income provides a large proportion of the financial support of retirees, a simple analysis will help understand the issues of the "aging population" in Australia.

The same analysis applies to personal income. If you own rental property and also work in an office, your total income(i) is made up of your paycheque from the office but also a contribution from capital(c) in the form of rent and capital gains. The two components of income can be related, as described in (Piketty, 2014) by the equation $\beta=c / i$ For example if your capital is equivalent to six years income then $\beta=6$ (years).

A familiar idea is the rate of return on capital, for example $r=5$ percent per annum could be the return on rental property. This means that the profit from capital in one year is 5 percent of the value of the capital. A useful concept used in (Piketty, 2014) is the share of income derived from capital denoted by $\alpha$ and given by the equation $\alpha=r \beta$. If $\beta=6$ and $r=5$ then $\alpha=30$ percent, which is the share of income from capital. This analysis can be done a many levels: following our example above, take a person who earns $\$ 100,000$ a year from paid work and also has a 5 percent from property valued at $\$ 600,000$. Then $\beta=6$ and $\alpha=30$ percent is the additional income derived from capital.

\section{THE GROWING IMPORTANCE OF CAPITAL}

The importance of Capital in the world economy and also in Australia since 1945 is shown in (Piketty, 2014) to be increasing using an impressive collection of economic data. This can be seen in Australia today when people complain about the high price of housing. The increasing proportion of income derived from Capital is also relevant to the considerations above about the ratio of employed to retirees.

On one hand, some retirees may not need the financial support through taxation assumed in (Intergenerational Report, 2015) because of their accumulated assets, which younger people and many immigrants do not have. But there will also be an increasing source of financial support for the "aging population" through taxation of capital gains.

\section{CONCLUSIONS}

Contrary to what is suggested in (Intergenerational Report, 2015), there is no crisis in the aging population. The ratio of employed to retirees can be adjusted by changing the level of immigrants (and putting a priority on younger people). Increased immigration is already happening and may already be changing the age proportions in the desired way. A second important factor which needs to be taken into account in a study of the aging population is the distribution and taxation of wealth.

\section{REFERENCES}

Commonwealth of Australia (2015). 2015 Intergenerational Report Australia in 2055. Commonwealth of Australia, Canberra.

Piketty, Thomas (2014). Capital in the Twenty-First Century. Harvard University Press, Cambridge Massachusetts. 